\title{
EDITORIAL
}

\section{A tribute: Abel Ayerza and pulmonary hypertension}

\author{
J.A. Mazzei and M.E. Mazzei
}

I $\mathrm{n}$ the history of research on pulmonary hypertension, one of the key landmarks was the clinical description of the disease, which was made in 1901 by Abel Ayerza.

From then on, in the international medical literature (especially the French, British and American literature), so-called "Ayerza's disease" encompassed various aetiological forms of pulmonary hypertension, discriminated today thanks to developments in the understanding of this disease and its current classification.

Abel Ayerza was born in Buenos Aires, Argentina, in 1861. After achieving a doctorate with a gold medal in 1886 from the School of Medicine at the University of Buenos Aries, he travelled to Paris, France where he specialised with Jean Martin Charcot and François Joseph Babinski at the Hôpital de la Salpêtrière, Pierre Carl Edouard Potain at the Hôpital de la Charité and François Sigismond Jaccoud at the Hôpital de la Pitié. On his return to Argentina, he joined the Hospital de Clínicas at the University of Buenos Aires, where, at the age of 37, he was appointed Professor of the First Chair of Medicine.

On August 20, 1901, Dr Ayerza described a patient with a history of chronic cough and sputum, dyspnoea, severe cyanosis, profound daytime sleepiness and manifestations of right heart failure. The patient was a 38-yr-old male who had suffered from pneumonia at 20 and 32 yrs of age and since then had had respiratory symptoms. Dyspnoea was severe at rest and there was central cyanosis, clubbed fingers and tachypnea. In the respiratory examination, wet crackles and wheezing were abundant in both lungs. In the cardiovascular examination there was jugular venous distension, hepatomegaly, hepatojugular reflux, ascites and oedema of lower limbs. The patient's blood pressure was $150 \mathrm{mmHg}$ with the Potain apparatus (at that time diastolic blood pressure was not determined) and heart rate was 112 beats per min. The laboratory examination revealed polycythemia of $6,560,000$ red blood cells per $\mathrm{mm}^{3}$ and white blood cells were 5,250 cells per $\mathrm{mm}^{3}$.

The patient died 24 days after admission and the autopsy showed dilated bronchi with thickened walls and abundant secretions. The heart was enlarged, weighing $480 \mathrm{~g}$, the right ventricular wall was thickened, the right atrium was dilated, the tricuspid valve ring was normal, the left atrium and ventricle were normal, the valves had no injuries and histological examination of the arteries showed hyperplasia of the middle

Dept of Medicine, University of Buenos Aires, Buenos Aires, Argentina.

CORRESPONDENCE: J.A. Mazzei, Dept of Medicine, University of Buenos Aires, Córdoba 2351, Buenos Aires 1125, Argentina. E-mail: jamazzei@gmail.com

PROVENANCE: Submitted article, peer reviewed.

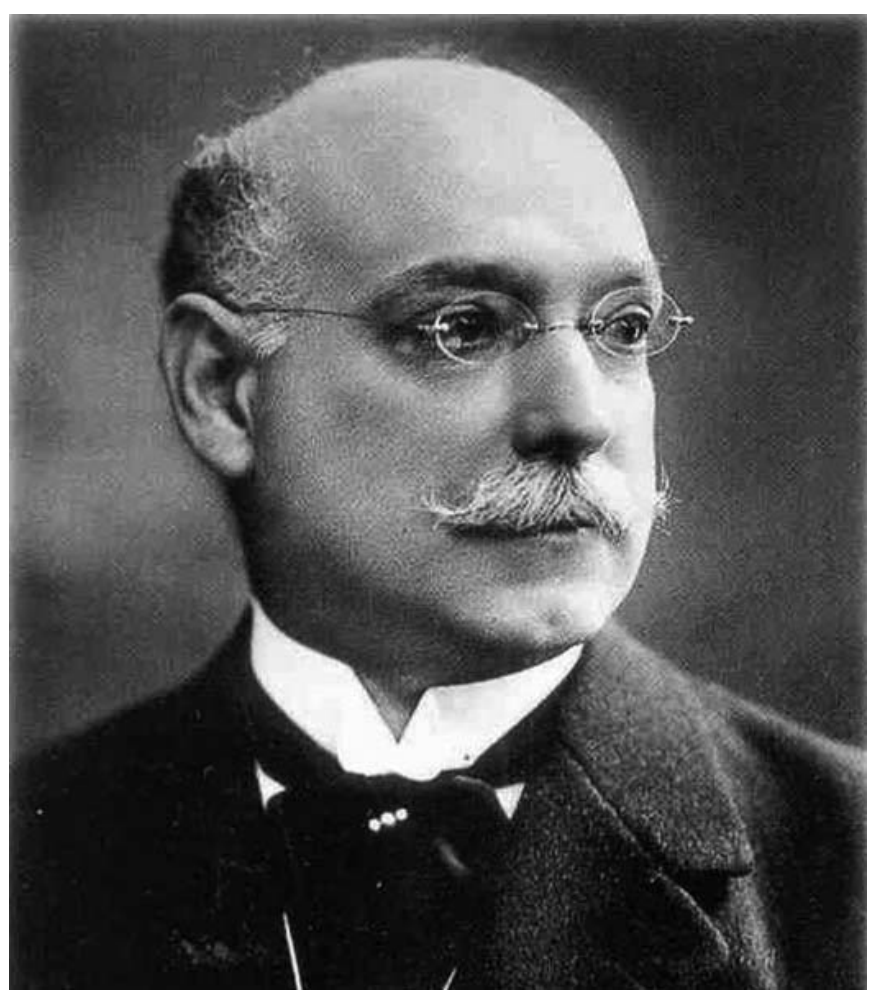

FIGURE 1. Portrait of Dr Abel Ayerza (courtesy of the Ayerza family).

layer and of the intima with the thrombus obstructing the lumen and, in some cases, newly formed channels.

This clinical picture was different from entities known at that time. In order to differentiate it from other diseases Dr Ayerza called it "cardíaco negro" (black cardiac) due to the extreme degree of cyanosis observed in these patients. Following this announcement, several publications about the disease were initiated in Argentina.

In 1905, Pedro Escudero described sclerosis of the pulmonary artery in a "black cardiac", considering it secondary to a chronic pulmonary process and, in 1911, indicated that the status of "black cardiac" was a result of comorbidity between syphilis and obliterating sclerosis of the pulmonary artery [1].

In 1912, Dr Ayerza and his student F.C. Arrillaga proposed that injury of the pulmonary artery was secondary to chronic lung processes and that sclerosis of the pulmonary artery would cause right heart hypertrophy. In the long-term, the impact of mechanical circulatory disturbances on a predisposed arterial tree would bring about the diffuse thickening of the pulmonary 
artery, which was the histopathological substrate of the "black cardiac".

In his doctoral thesis, F.C. Arrillaga selected a group of 11 patients with similar characteristics, including the description of the patient presented by Dr Ayerza [2]. In his thesis, although there were some common findings, the aetiology of pulmonary hypertension was not the same in all cases. In 1913, F.C. Arrillaga published a review of the aetiology, pathogenesis, pathology, symptomatology, radiology, evolution, prognosis and treatment of the disease [3].

As a result of these publications the disease became known worldwide as "Ayerza's disease". In the 34th Annual Meeting of the American Society for Medicine in 1919, WARTHIN [4] described the first case in English and recognised in the USA: "A case of Ayerza's disease: chronic cyanosis, dyspnoea, and erythremia associated with syphilitic arteriosclerosis of the pulmonary artery."

In 1920, ElizALDE and ArRILlaga [5] indicated that the anatomical substrate was the primitive sclerosis of the pulmonary artery of syphilitic aetiology, lung injury was not essential to develop Ayerza's disease, and in some cases the arterial injury could be primary and not secondary to a pulmonary process.

Between 1924 and 1927, F.C. Arrillaga presented seven new cases on which he based his theory. He then argued that sclerosis of the pulmonary artery was always primary and that it could be isolated or secondary to chronic pulmonary processes [6]. The theory of primary sclerosis of the pulmonary artery as a cause of Ayerza's disease, independent of the presence of a chronic pulmonary process, guided the pathogenesis towards pulmonary hypertension later called "primary" and, currently, "idiopathic" [7].

In 1949, TIDY [8] stated that "Ayerza's disease was first fully described in a monograph by Arrillaga, of Buenos Aires, in 1912. Arrillaga claims that it is a morbid entity with a fairly constant clinical course and picture terminating with cardiac failure and an extreme degree of cyanosis, the latter feature leading him to give it the name "cardiacos negros". The subjects are adults. The predominant pathological change is sclerosis of the pulmonary artery and its branches. The lungs also show chronic changes, a fact which brings the entity into the group of cardio-pulmonary diseases. The aetiology and the cause of the extreme cyanosis have been regarded as somewhat of a mystery. Syphilis was formerly thought to be the cause of the pulmonary arteritis, but this has been disproved. Since the publication of this monograph a number of cases considered to be of a similar nature have been recorded under such titles as Ayerza's disease, pulmonary arteriosclerosis, and sclerosis of the pulmonary vessels. These cases form a motley group. They come from various parts of the world in small numbers, often single examples. The subjects are of all ages, many in very early life. In a few instances the aetiology is obvious - such as those cases with congenital cardiac lesions. An occasional case is claimed to be syphilitic. Many are ascribed to the end results of chronic lesions of the lung parenchyma, thus belonging to the cardio-pulmonary group. When advanced cor pulmonale has developed and the heart fails there is inevitably cyanosis, but only in a few instances has it approached the extreme degree described by Arrillaga. This heterogeneous collection of cases of varying aetiology and manifestations clearly cannot explain the frequency and the consistent features of the disease described in Brazil."

It was only in 1951 that DRESDALE et al. [9] haemodynamically identified "primary" pulmonary hypertension and gave it the name that was used for many years until it was changed to the current name of "idiopathic" pulmonary arterial hypertension. What Dr Ayerza described in 1901, when there was no chest radiograph or electrocardiogram, let alone cardiac catheterisation, and when laboratory contributions were still precarious, was probably what is now known as severe pulmonary hypertension in a patient with pulmonary parenchymal disease, and it was his student, F.C. Arrillaga, who established that the disease could occur as primary lesions of pulmonary vessels without pulmonary pathology.

\section{STATEMENT OF INTEREST}

None declared.

\section{REFERENCES}

1 Escudero P. The Black Cardiacs and the Ayerza's disease. Paris, Revue Critique, 1911.

2 Arrillaga FC. Esclerosis secundaria de la arteria pulmonar y su cuadro clínico (cardiacos negros) [Secondary sclerosis of the pulmonary arteryand its clinical findings (black cardiac)]. PhD Thesis. University of Buenos Aires, Argentina, 1912.

3 Arrillaga FC. Sclèrose de l'artère pulmonaire secondaire a certains états pulmonaires chroniques (cardiaques noires) [Sclerosis of the pulmonary artery secondary to certain chronic pulmonary diseases (black cardiacs)]. Arch Mal Coeur 1913; 6: 518-529.

4 Warthin AS. A case of Ayerza's disease. JAMA 1919; 76: 716.

5 Elizalde PI, Arrillaga FC. Caracteres histopatológicos en la enfermedad de Ayerza [Histopathological findings in Ayerza's disease]. Revista de la Asociación Médica Argentina 1920; 32: 613-628.

6 Arrillaga FC, ed. La Arteritis Pulmonar: Cardiacos Negros [Pulmonary Arteritis: Black Cardiacs]. Buenos Aires, Pedro Garcia, 1925.

7 Castex M, Capdehourat EL, Mazzei ES. Resultados del estudio broncográfico en los cardiacos negros [Results of bronchographics studies in black cardiacs]. Roentgen 1937; 1: 5-12.

8 Tidy H. Ayerza's disease, silicosis, and pulmonary bilharziasis. $\mathrm{Br}$ Med J 1949; 1: 977.

9 Dresdale DT, Schultz M, Michtom RJ. Primary pulmonary hypertension: I. Clinical and hemodynamic study. Am J Med 1951; 11: 686. 